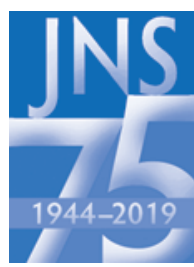

\title{
Cavernous angiomas: deconstructing a neurosurgical disease
}

\author{
JNSPG 75th Anniversary Invited Review Article
}

\author{
Issam A. Awad, MD, and Sean P. Polster, MD \\ The Neurovascular Surgery Program, Section of Neurosurgery, University of Chicago Medicine and Biological Sciences, \\ Chicago, Illinois
}

Cavernous angioma (CA) is also known as cavernoma, cavernous hemangioma, and cerebral cavernous malformation (CCM) (National Library of Medicine Medical Subject heading unique ID D006392). In its sporadic form, CA occurs as a solitary hemorrhagic vascular lesion or as clustered lesions associated with a developmental venous anomaly. In its autosomal dominant familial form (Online Mendelian Inheritance in Man \#116860), CA is caused by a heterozygous germline loss-of-function mutation in one of three genes-CCM1/KRIT1, CCM2/Malcavernin, and CCM3/PDCD10—causing multifocal lesions throughout the brain and spinal cord.

In this paper, the authors review the cardinal features of CA's disease pathology and clinical radiological features. They summarize key aspects of CA's natural history and broad elements of evidence-based management guidelines, including surgery. The authors also discuss evidence of similar genetic defects in sporadic and familial lesions, consequences of CCM gene loss in different tissues at various stages of development, and implications regarding the pathobiology of CAs. The concept of $\mathrm{CA}$ with symptomatic hemorrhage $(\mathrm{CASH})$ is presented as well as its relevance to clinical care and research in the field. Pathobiological mechanisms related to CA include inflammation and immune-mediated processes, angiogenesis and vascular permeability, microbiome driven factors, and lesional anticoagulant domains. These mechanisms have motivated the development of imaging and plasma biomarkers of relevant disease behavior and promising therapeutic targets.

The spectrum of discoveries about CA and their implications endorse CA as a paradigm for deconstructing a neurosurgical disease.

https://thejns.org/doi/abs/10.3171/2019.3.JNS181724

KEYWORDS cavernous; angioma; hemangioma; cavernoma; vascular malformation; hemorrhagic stroke; epilepsy; vascular disorders

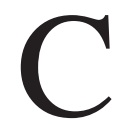
AVERNOUS angioma (CA) is also known as cavernoma, cavernous hemangioma, and cerebral cavernous malformation (CCM) (National Library of Medicine Medical Subject heading Unique ID D006392). In its sporadic form, CA occurs as a solitary hemorrhagic vascular lesion or as clustered lesions associated with a developmental venous anomaly (DVA). ${ }^{1}$ In its autosomal dominant familial form (Online Mendelian Inheritance in Man no. 116860), CA is caused by a heterozygous germline loss-of-function mutation in one of three genes-CCMI/ KRIT1, CCM2/Malcavernin, and CCM3/PDCD10 ${ }^{12,20,29,39}$, $40,51,55$ - that causes multifocal lesions throughout the brain and spinal cord. A founder mutation (Q455x) involving KRITl and an associated preserved haplotype accounts for clustering of familial CA disease in Hispanic Americans of Mexican descent, ${ }^{40}$ and a common deletion in the CCM2/Malcavernin accounts for clustering among Ashkenazi Jews. ${ }^{28}$

ABBREVIATIONS $C A=$ cavernous angioma; $\mathrm{CASH}=\mathrm{CA}$ with symptomatic hemorrhage; $\mathrm{CCM}=$ cerebral cavernous malformation; $\mathrm{CD} 14=$ cluster of differentiation 14 ; $\mathrm{DCEQP}=$ dynamic contrast enhanced quantitative perfusion; $\mathrm{DVA}=$ developmental venous anomaly; $\mathrm{FDR}=$ false discovery rate; MEKK = mitogen-activated protein kinase kinase; QSM = quantitative susceptibility mapping; SCD14 = soluble form of CD14; sROBO4 = soluble form of Roundabout 4; SRS = stereotactic radiosurgery; SWI/VenBold = susceptibility weighted imaging/BOLD venographic imaging; TLR4 = toll-like receptor 4; T2*/GRE = gradient recalled echo acquired; VEGF = vascular endothelial growth factor.

SUBMITTED March 7, 2019. ACCEPTED March 15, 2019.

INCLUDE WHEN CITING DOI: 10.3171/2019.3.JNS181724. 

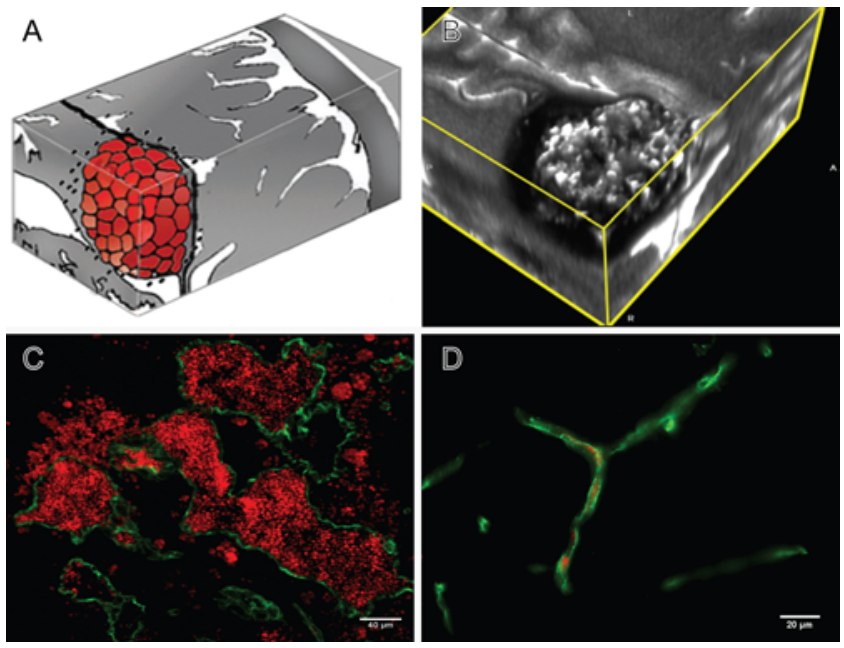

FIG. 1. A: Artist rendition of the mulberry-like CA. B: 3D MRI slab of a human lesion, T2 acquisition at 3 Tesla, highlighting the characteristic "popcorn appearance" of a CA with a hemosiderin ring. C: Confocal immunofluorescence photomicrograph with staining (CD31, green) of endothelial cells (ECs) lining the lesion's vascular spaces (caverns). Red blood cells (red) fill the caverns and extravasate beyond the "leaky" endothelium. Bar $=40 \mu \mathrm{M}$. D: Comparative image of normal brain capillaries. Bar $=20 \mu \mathrm{M}$.

The lesion is histologically identical in association with all genotypes, characterized by grossly dilated vascular spaces (known as "caverns") lined by a single layer of endothelium, lacking mature vessel wall angioarchitecture, and manifesting features of chronic hemorrhage in adjacent neuroglial parenchyma ${ }^{79}$ (Fig. 1). The gross appearance of the lesion has been likened to a mulberry. Familial lesions have been shown to harbor biallelic mutations in endothelial cells (ECs) lining the pathological vascular channels.,30 This observation is consistent with a Knudsonian mechanism that involves a homozygous loss of function in the lesion endothelium, while all cells in the body are heterozygous for the inherited gene. Lesions surgically resected from sporadic cases lacking inherited germline mutations harbor somatic mutations of the same three $C C M$ genes. This indicates identical molecular mechanisms related to $C C M$ gene loss of function in both familial and sporadic lesions. ${ }^{64}$

In this review, we have applied conventional and distinct rules of nomenclature for disease, lesion, human gene, mouse gene, and protein. Both the human disease and the vascular lesion characterizing the phenotype are designated as cavernous angioma (CA), which is also known as cerebral cavernous malformation (CCM). Human genes associated with familial CA are fully capitalized and italicized as $C C M 1, C C M 2$, and $C C M 3$, whereas murine genes are italicized with both upper- and lower-case letters and appear as $C \mathrm{~cm} 1, C \mathrm{~cm} 2$, and $C \mathrm{~cm} 3$. To avoid confusion, we refer to the respective gene products by their protein database names: KRIT1, Malcavernin (or OSM), and PDCD10, respectively. By following these rules, referencing the disease, a vascular lesion, a gene (mouse or human), or a protein should be interpretable.

Histologically identical CA lesions arise in the brain after irradiation, ${ }^{22}$ which is not surprising in view of the propensity of radiation to cause somatic mutations. Vascular hyperpermeability in the irradiated brain may also play a role, as may radiation-induced hemorrhagic microangiopathy ${ }^{98}$ - both described in the spectrum of pathology leading to radionecrosis. Other extradural lesions with the histological features of CA have been described, ${ }^{47,84}$ but those lesions do not occur with the genetically inherited disease nor have they been related to its mechanisms. In this review, we will not address radiation-induced nor extradural CAs.

\section{Historical Paradigms Defining the Cavernous Angioma}

There is no evidence that cerebrovascular angiomas were recognized in antiquity. With the advent of postmortem examinations and clinical pathological correlations, vascular lesions became recognized in association with seizures or apoplexy (hemorrhagic stroke). Virchow first attempted to classify cerebrovascular malformations. ${ }^{100}$ Subsequent pathologists, mostly in the German schools, struggled with the lesions' classification as angiomatous tumors versus developmental anomalies. Others avoided this controversy and employed the term "hamartoma" or "tumor-like anomalies" (geschwulstartige fehlbildungen). ${ }^{86}$ Cushing and Bailey commented extensively on cavernomas (angioma cavernosum) in their classical treatise. ${ }^{21}$ With the introduction of cerebral angiography and the growing recognition of, and interest in, arteriovenous malformations, cavernomas were understood in the context of "cryptic" or angiographically occult vascular malformations, as described by Russell. ${ }^{82,83}$ The currently recognized pathological features of CAs were further clarified by McCormick, ${ }^{62}$ before being more conclusively defined, with a clearer correlation with MRI features..$^{13,79}$

\section{Imaging Features}

The advent of MRI ushered in an era of better detection and more precise definition of cerebrovascular pathologies including CA. While CT had revealed CAs as nonspecific ill-defined calcifications, MRI clearly defines the typical "popcorn appearance" of the lesion, which highlights larger caverns, with mixed signals of blood at different stages of organization and calcifications, and surrounding hemosiderin (Fig. 1B). The latter "hemosiderin ring" is best appreciated on T2-weighted sequences. ${ }^{16,77}$ Acute hemorrhage may mask underlying cavernomas on MRI as on CT, but the typical lesion emerges on serial MRI with clearance of acute blood. In all, MRI allows the diagnosis of asymptomatic lesions as well as those associated with epilepsy and recent bleeding, and reveals multifocal lesions in familial cases and associated venous anomalies (Fig. 2).

Gradient recalled echo acquired (T2*/GRE) sequences reveal the "blooming" effect of hemosiderin, increasing the sensitivity of detection of CAs. Susceptibility weighted imaging (SWI/VenBold) sequences, particularly those obtained at 3 Tesla, can reveal a greater number of multifocal lesions in familial cases, which do not appear on more conventional and T2*/GRE images. These sequenc- 

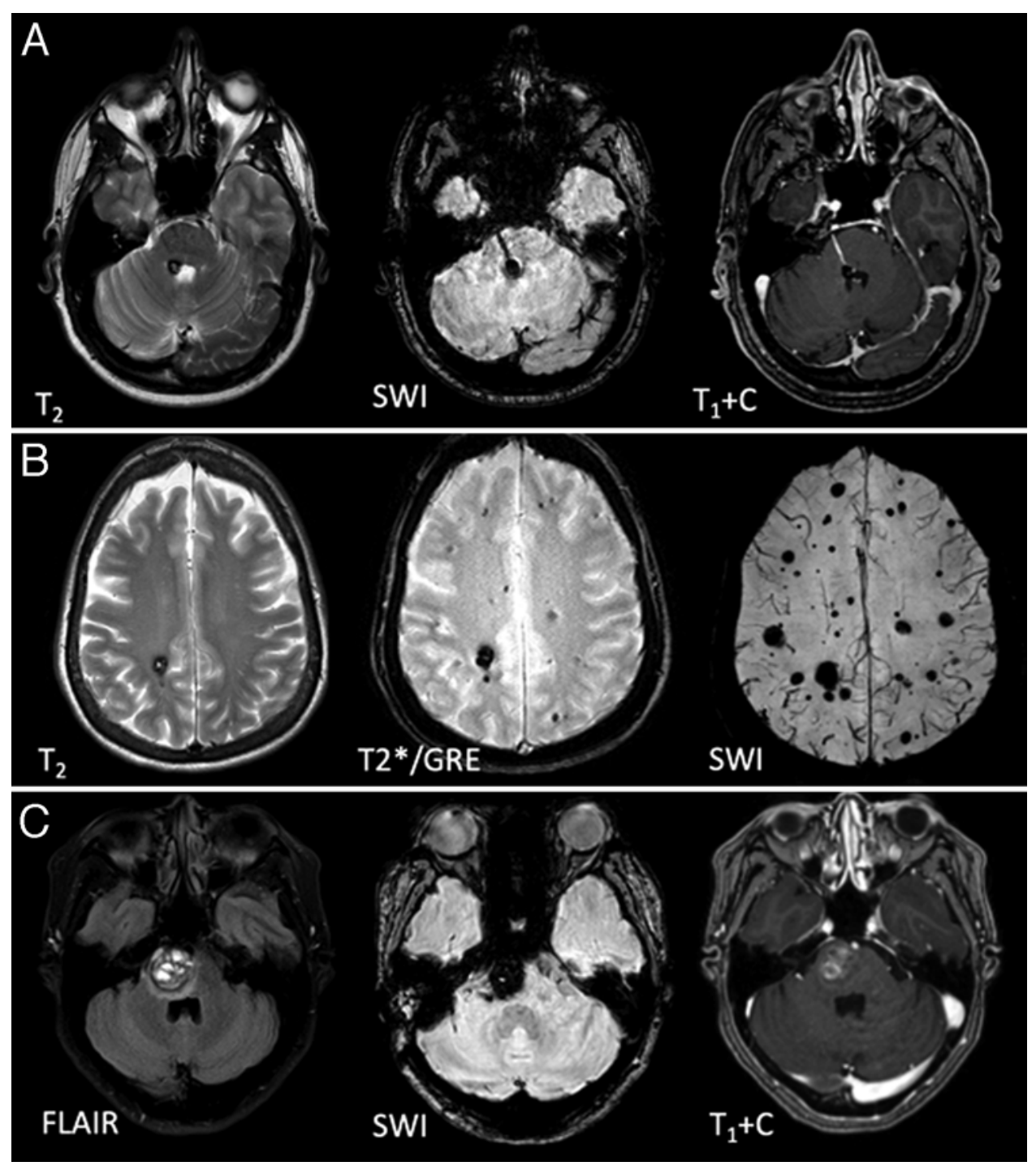

FIG. 2. MRI features of CA. A: MRI features of a solitary CA at the floor of the 4th ventricle, clustered around a developmental venous anomaly traversing the pons. B: Autosomal dominant familial multifocal CAs, including punctate lesions on SWI, which are not seen on conventional (T2 and GRE-weighted) sequences. C: Pontine CA with the characteristic features of symptomatic hemorrhage, with acute blood expanding the lesion with a surrounding fluid-attenuated inversion recovery (FLAIR) signal of edema (left). $\mathrm{T} 1+\mathrm{C}=$ contrast-enhanced T1-weighted image.

es reveal more than twice the lesion burden identified on conventional MRI as well as a greater number of lesions with advancing age in familial cases. ${ }^{23,24}$ Some of these occult lesions may progress to larger lesions or hemorrhages. This enhanced sensitivity has created a differential diagnostic challenge with hemorrhagic microangiopathy or cerebral microbleeds, particularly in the aging brain, and with some cases of hemorrhagic metastases that need to be considered in the appropriate clinical context. ${ }^{94}$

MRI also allows functional imaging of primary sensorimotor, speech, and visual cortical areas, and their white matter connectome by diffusion tensor imaging, which has enhanced surgical planning. ${ }^{27,85}$ New MRI techniques of quantitative susceptibility mapping (QSM) and dynamic contrast enhanced quantitative perfusion (DCEQP) have been developed to measure iron deposi- tion and vascular permeability in $\mathrm{CAs}^{67}$ (Fig. 3), and are being assessed as potential biomarkers of clinically relevant disease activity.

\section{Natural History and Why CASH Matters}

Patients with CA typically present with a broad range of symptoms, most often during the 2nd to 5th decades of life. The most frequent clinical manifestations of CAs include seizures (50\%), symptomatic hemorrhage (25\%), and focal neurological deficits without radiographic evidence of recent hemorrhage (25\%) (Fig. 4). ${ }^{5}$ Nevertheless, $20 \%-50 \%$ of CA patients have no symptoms, and their disease is identified incidentally due to the widespread accessibility and utilization of brain MRI. Early natural history studies reported a wide range of hemorrhage frequencies, in part due to variances in definition. Thus, the 

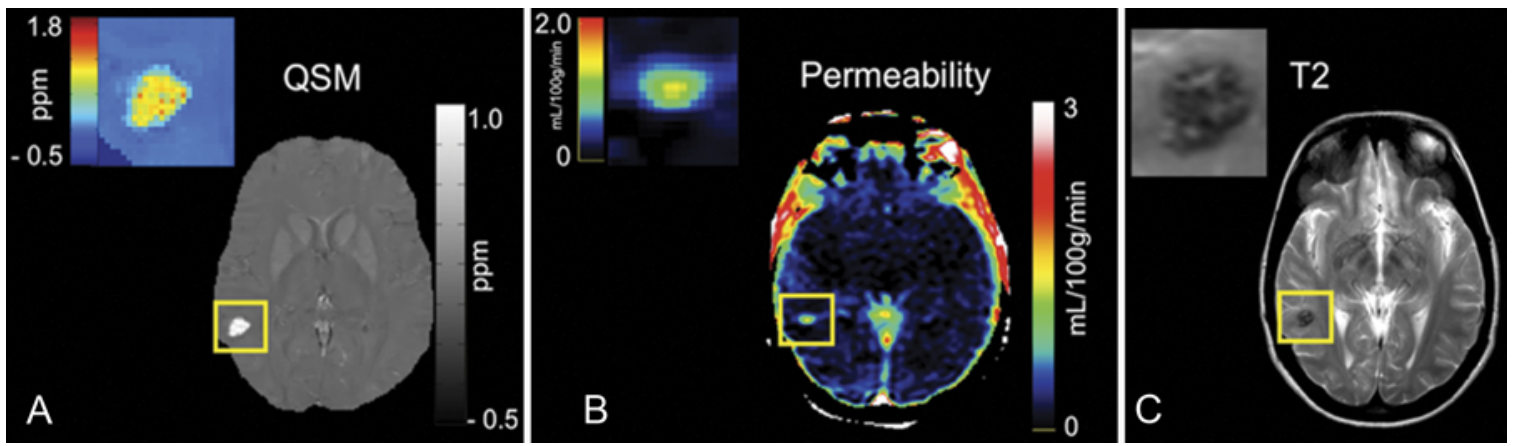

FIG. 3. A: QSM image of a CA shown with a color-coded map of iron content (ppm). B: DCEQP permeability map of the same lesion with color scale $\mathrm{K}_{\mathrm{i}}$ units ( $\left.\mathrm{ml} / 100 \mathrm{~g} / \mathrm{min}\right)$. C: T2-weighted image of the same lesion, provided for lesion size and definition of "region of interest" for the lesional QSM and DCEQP assessment. Figure reproduced with permission from Mikati AG, Tan H, Shenkar R, et al.: Dynamic permeability and quantitative susceptibility: related imaging biomarkers in cerebral cavernous malformations. Stroke 45:598-601, 2014.

definition of symptomatic hemorrhage was standardized in 2008 as "requiring acute or subacute onset of symptoms...accompanied by radiological, pathological, surgical, or rarely only cerebrospinal fluid, evidence of recent extra- or intralesional hemorrhage."4

In population studies and in case series without selection criteria, the risk of first symptomatic hemorrhage has been found to be extremely low $(0.08 \%$ per patient-year) among incidentally identified CAs. ${ }^{5,68}$ However, once a symptomatic hemorrhage has occurred, the annual risk of a subsequent episode of bleeding is dramatically increased-at least 10-fold by most estimates. ${ }^{2,5,44}$ This elevated risk is greatest soon after a hemorrhage but persists thereafter, with a 5-year risk estimated at $42 \%(95 \%$ CI 27\%-58\%). Brainstem lesions are also associated with a greater risk of initial bleeding and recurrent symptomatic hemorrhage, $, 444,78$ although it is unclear if this is related to a sensitivity bias, in which tiny bleeds are more likely symptomatic in an eloquent location. Bleeding is also more frequent and occurs earlier in CCM3 familial cases with $P D C D 10 / C C M 3$ mutations, but this appears to be related to the development of exceptional lesion burden at an early age, rather than the greater risk of bleeding associated with individual lesions. ${ }^{89}$

There are fewer than 200,000 cases of CA with symptomatic hemorrhage (CASH) among the more than 1 million patients with $\mathrm{CA}$ in the United States. Hence, CASH represents a singular clinical entity, distinguishing lesions that impact a patient's life and merit clinical intervention. Given their high risk of rebleeding and the high cost and potential risks of their surgical excision, particularly when identified in brainstem locations, CASHs are currently the primary focus of therapeutic development aimed at stabilizing and preventing rebleeding. ${ }^{72}$

\section{Evidence-Based Management Guidelines}

Despite many publications about CAs, there remains controversy regarding optimal diagnostic and management strategies. The Angioma Alliance, which is the primary patient support group in the US advocating on behalf of patients and research in CA, assembled a multidisciplinary writing group with expert clinicians to help summarize the existing literature in the clinical care of CA, focusing on five topics: 1) epidemiology and natural history, 2) genetic testing and counseling, 3) diagnostic criteria and radiology standards, 4) neurosurgical considerations, and 5) neurological considerations. Participants of the writing group reviewed literature, rated evidence, developed recommendations, and established consensus, controversies, and knowledge gaps according to a prespecified protocol. Of 1,270 publications (January 1, 1983, to September 31 [sic], 2014), they selected 98 based on methodological criteria and identified a further 38 recent or relevant publications. These publications were used by topic editors to summarize current knowledge about CA and to make 23 management recommendations, which were rated by class (size of effect) and level (estimate of certainty) according to the American Heart Association/American Stroke Association criteria. The guidelines were peer-reviewed and published in 2017, ${ }^{2}$ with more detailed content available online (www.angioma.org/ccmguidelines). Because no reports of randomized controlled trials were available, no recommendation was level A; however, 11 (48\%) were level B and 12 (52\%) were level C. The writing group's recommendations were class I in 8 (35\%), class II in $10(43 \%)$, and class III in $5(22 \%)$. The generally low levels of proposed recommendations and classes require further research to better inform clinical practice.

\section{Surgical Opportunities and Challenges}

The recently compiled guidelines for evidence-based CA management ${ }^{2}$ note that there have been no reports of randomized controlled trials comparing resection to conservative treatment and that most case series contributing to systematic reviews harbor substantial biases and lack adjudicated outcomes. ${ }^{75}$ A population-based study revealed poorer outcome over the 5 years following surgery or initiation of medical/conservative management, and a higher risk of symptomatic hemorrhages and focal neurological deficits in CA cases treated surgically than in those treated medically. ${ }^{69}$ However, that study was not randomized and, clearly, the patients treated surgically were sicker and more likely to experience bleeding from the CA prior to surgery. Nevertheless, the benefits of surgery 


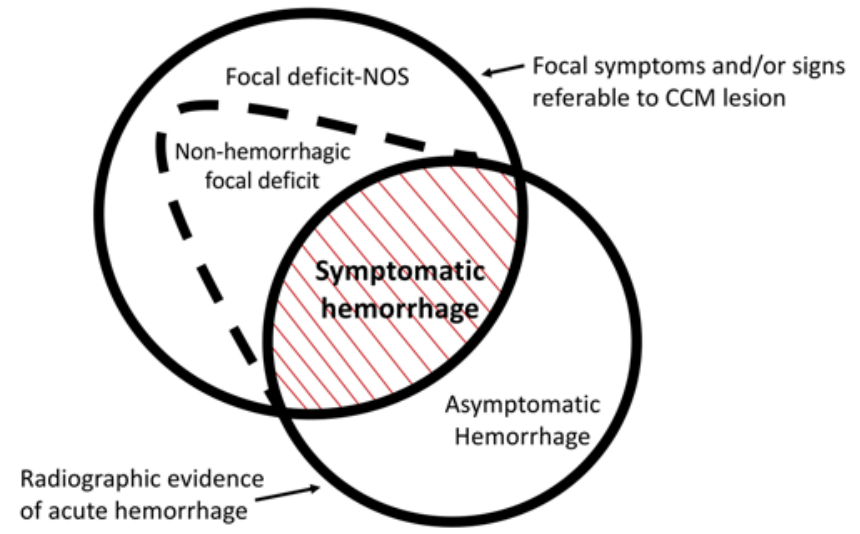

FIG. 4. Spectrum of clinical manifestations of CAs. Symptomatic hemorrhage, with a rigorously adjudicated definition, is a singular clinical event with distinct clinical implications regarding future risk and deploying clinical interventions. Figure modified with permission from Al-Shahi Salman R, Berg MJ, Morrison L, Awad IA: Hemorrhage from cavernous malformations of the brain: definition and reporting standards. Angioma Alliance Scientific Advisory Board. Stroke 39:3222-3230, 2008.

for CA cannot be taken for granted, and it is important to weigh the risk of surgery versus the natural history of CAs in specific clinical scenarios and lesion locations.

Case series generally report low rates of surgical morbidity and mortality for supratentorial CAs, but much higher rates for brainstem lesions. ${ }^{75}$ Surgical complication rates, however low, clearly exceed the low risks from hemorrhage in lesions that have never bled. Hence surgical excision of asymptomatic lesions, particularly those lying deep or in brainstem locations are almost never justified. Nevertheless, this same risk appears more favorable when compared to the risk of recurrent intracranial hemorrhage following a CA hemorrhage. Depending on the location of the CA, the risk of resection can vary widely, and this is taken into account when making surgical decisions. Thus, resection is generally recommended for symptomatic, easily accessible CAs, given the increased risk of repeated bleeding after the first hemorrhage and the low level of morbidity associated with surgery.

Deeper CAs located in the insula, basal ganglia, or thalamus require a more technically challenging surgery involving critical structures, including deep nuclei and white matter tracts, and the risk of injury to small perforating arteries. For very experienced teams, the postoperative morbidity rate associated with these CAs is 5\%-18\%, with the rate of mortality approaching $2 \%$; many patients ultimately attain recovery from severe disability ${ }^{37,71}$ Surgery for brainstem CAs is associated with an even greater early morbidity rate in nearly half the cases, but most patients also recover significantly over time. ${ }^{38,75}$ Skull base approaches can facilitate resection of brainstem lesions. ${ }^{73}$ It is believed that technical adjuncts, such as image guidance, ${ }^{27,105}$ neurophysiological monitoring, ${ }^{112}$ and laserassisted technique, ${ }^{18}$ improve the outcome of resection strategies when used in eloquent areas; however, there are limited controlled studies to support specific modalities. Severe disability may occur as a result of recurrent hemorrhages as well as surgery in deep eloquent locations and the brainstem, raising a real controversy about the timing and threshold for surgical decisions vis-à-vis prior functional status. The immediate consequences of surgery for brainstem lesions are easier to justify in a patient who has suffered more than one hemorrhage or greater disability after a prior bleed. Spinal CAs pose a similar challenge, with most reports documenting outcomes akin to brainstem CAs and advocating similar treatment decisions. ${ }^{9}$

Control of medically refractory seizures due to CA can be safely achieved by microsurgical resection of the $\mathrm{CA}$, provided the lesion is solitary and it correlates with seizure semiology and electrophysiological localization. ${ }^{80}$ There is a lower chance of seizure control with lesionectomy in cases in which the preoperative duration of seizures is long and in cases of multiple lesions. There is a good argument for early surgery in patients with a solitary lesion and recent onset of lesion-localizable seizures, as these patients can attain a life that is free from seizure, lesion, and in many cases, anticonvulsant drugs. ${ }^{19}$ In patients with longstanding recalcitrant seizures, there is a better likelihood of seizure control if hemosiderin surrounding the lesion can be removed safely, and when resection of adjacent mesiotemporal structures is performed in cases with temporal lobe epilepsy and associated memory dysfunction or hippocampal atrophy. ${ }^{7,11,80,101}$ Recent reports suggest a role for laser fiber ablation of CAs as a potentially promising treatment of associated epilepsy. ${ }^{104}$

There are conflicting data on resection of a DVA associated with CA, with most authors advocating DVA preservation to prevent serious complications such as edema, hemorrhage, and/or venous infarctions. ${ }^{111}$ In general, a DVA can only be resected if it is very small, or if the brain it drains is also being resected (as in rare cases of modified lobectomies for regional venous dysmorphism and seizures). ${ }^{7}$

Stereotactic radiosurgery (SRS) has been suggested as an alternative treatment for symptomatic CA located in eloquent areas, with most series identifying a decline in the hemorrhage rate more than 2 years after SRS treatment. ${ }^{59}$ Causality cannot be inferred, however, as most natural history studies also demonstrate decreasing rebleeding rates after 2 years posthemorrhage. Recently, authors conducted a retrospective study of SRS comparing patients treated for their first brainstem hemorrhage with patients treated for a second hemorrhage; the authors found no significant difference in annual bleeding rates between the two groups. ${ }^{54}$ There is legitimate concern whether radiation exposure may enhance the genesis of new CAs in children and in familial cases. ${ }^{42}$ Complications from SRS are not trivial, particularly with lesions in eloquent areas deemed at high risk for resection, and the optimal SRS dose to reduce hemorrhage is not known. ${ }^{49}$

The following consensus recommendations regarding CA surgery were proposed based on current evidence, following vetting using the Delphi technique ${ }^{2,45}$ (the classes and levels of evidence are listed according to the American Heart Association criteria ${ }^{43}$ ):

1. Surgical resection is not recommended for asymptomatic CA, especially if located in eloquent, deep, brainstem or spinal location, nor in cases with multiple asymptomatic lesions (class III, level B). 
2. Surgical resection may be considered in solitary asymptomatic CA if easily accessible in noneloquent area, to prevent future hemorrhage, because of psychological burden, expensive and time-consuming follow-ups, to facilitate lifestyle or career decisions, or in patients who might need to be on anticoagulation (class IIb, level C).

3. Early surgical resection of CA causing epilepsy should be considered, especially when medically refractory epilepsy, in the absence of uncertainty about lesion epileptogenicity (class IIa, level B).

4. Surgery may be considered in symptomatic easily accessible CA lesions, with mortality and morbidity equivalent to living with the lesion for about 2 years (class IIb, level B).

5. Surgical resection may be considered in deep CA lesions if symptomatic or after prior hemorrhage, with mortality and morbidity equivalent to living with the lesion for 5-10 years (class IIb, level B).

6. After reviewing the high risks of early postoperative mortality and morbidity and impact on quality of life, it may be reasonable to offer complete surgical resection of brainstem CA after a second symptomatic bleed as those lesions have a more aggressive course (class IIb, level B).

7. Indications for resection of brainstem $\mathrm{CA}$ after a single disabling bleed, or for spinal CAs, are weaker (class IIb, level C).

8. Radiosurgery may be considered in solitary CA lesions with previous symptomatic hemorrhage if the lesion lies in eloquent areas that carry an unacceptable high surgical risk (class IIb, level B).

9. Radiosurgery is not recommended for asymptomatic CAs, for lesions which are surgically accessible, and in familial CA disease with concern about de novo lesion genesis (class III, level C).

(Modified with permission from the Angioma Alliance from Akers A, et al: Neurosurgery 80:665-680, 2017.)

\section{Lesion Pathobiology}

Beyond their salient histopathological features, human CA lesions harbor evidence of enhanced angiogenic activity and a proliferative index of ECs lining the caverns. ${ }^{81}$ They exhibit defective interendothelial junctions, ${ }^{106}$ and the peri-endothelial layer lacks mature smooth muscle cells, ${ }^{99}$ with the lesions exhibiting iron deposits, gliosis, and a robust inflammatory cell infiltration, including Bcells, plasma cells, and B- and T-cell clusters as well as oligoclonal immunoglobulins. ${ }^{90}$ Microdissected B-cells from CA lesions demonstrate antigen-driven clonal expansion and complement activation. ${ }^{91}$ Additionally, human CA lesions have recently been shown to involve clonal expansion of a fraction of ECs in the walls of caverns harboring the $C C M$ mutations..$^{25}$ These features are common to all lesion locations and genotypes.

Murine models have been developed in $\mathrm{Ccml}, \mathrm{Ccm} 2$, or $C \mathrm{~cm} 3$ heterozygous mice, in a background of genetic instability favoring somatic mutations (Trp53 or Msh2 loss). Consistent with Knudson's two-hit hypothesis, these mice develop a rich repertoire of CA lesions that increase throughout life, recapitulating the human disease (Fig.
5). ${ }^{63}$ The $C c m 3$ models have a more robust lesion burden, as with the human disease. ${ }^{89}$ Mature multicavernous lesions exhibit all of the known phenotypical signatures of the human lesion, including ECs lining the caverns lacking the respective CCM protein, a defective EC barrier, a high EC proliferative index, chronic bleeding with iron deposition, and a robust inflammatory response. Primitive single caverns (ballooned capillaries) are also seen in these models (Fig. 5), indicating the primordial CA lesion. The latter is consistent with capillary telangiectasia, with ECs lacking the CCM protein but not manifesting any bleeding, iron deposit, or inflammation. The evolution of CAs from capillary telangiectasias, previously proposed based on pathological observations, ${ }^{8}$ now seems confirmed by lesion genesis in mice.

Robust development of clustered CA lesions can also be induced in the mouse hindbrain with a conditional endothelial homozygous knockout of $C \mathrm{cml}, \mathrm{Ccm} 2$, or $C \mathrm{~cm} 3$ genes in the first postnatal days, during ongoing active vasculogenesis in the early postnatal mouse hindbrain (Fig. 5). ${ }^{110}$ These acute models allow rapid testing of signaling aberrations and rescue of lesion development while the more chronic models are better suited for preclinical testing of pharmacotherapy, including therapeutic effects on lesional hemorrhage and inflammation. Both models can be imaged using micro-CT, allowing a high-throughput assessment of lesion burden and quantitative analyses (Fig. 5). ${ }^{36}$

\section{Consequences of CCM Gene Loss}

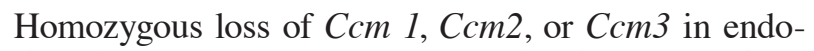
thelium is lethal to the embryo, resulting in gross defects in the heart and aortic development. ${ }^{48,103}$ This is mediated by endothelial gain of MEKK3-KLF2/4 signaling in early embryonic development. CA lesions arise from the same gain of MEKK3-KLF2/4 signaling in brain microvascular endothelium with postnatal loss of $C C M$ genes, bypassing embryonic lethality. ${ }^{113}$ This leads to a number of consequent signaling aberrations, including downstream Rho-A kinase (ROCK) activation, which provokes endothelial barrier dysfunction. ROCK inhibition can rescue the CCM phenotype in endothelium and prevents lesion formation, maturation, and hemorrhage ${ }^{65,93}$ Other signaling aberrations involve dysangiogenesis; ${ }^{46,107}$ endothelial-mesenchymal transition; ${ }^{60}$ proinflammatory state, oxidative stress, and autophagy: ${ }^{70,76}$ loss of TSP $1,{ }^{56}$ and thrombomodulinassociated local anticoagulant domains. ${ }^{57}$ Lesion development is also driven by lipid polysaccharide signaling through CD14/TLR4 receptors on brain microvascular ECs, and this has been related to a robust impact of gramnegative bacteria in the gut microbiome on lesion development. ${ }^{97}$

Heterozygous CCM mutations have been correlated with increased vascular permeability in the skin, lung, and brain, ${ }^{93,103}$ even in the absence of lesions, which has been confirmed in humans ${ }^{66}$ The physiological and clinical consequences of this generalized hyperpermeability are not known, but they are the subject of intense investigations.

Loss of $\mathrm{Ccm} 3$ function in neuroglia also results in a phenotype that includes disruption of brain development 

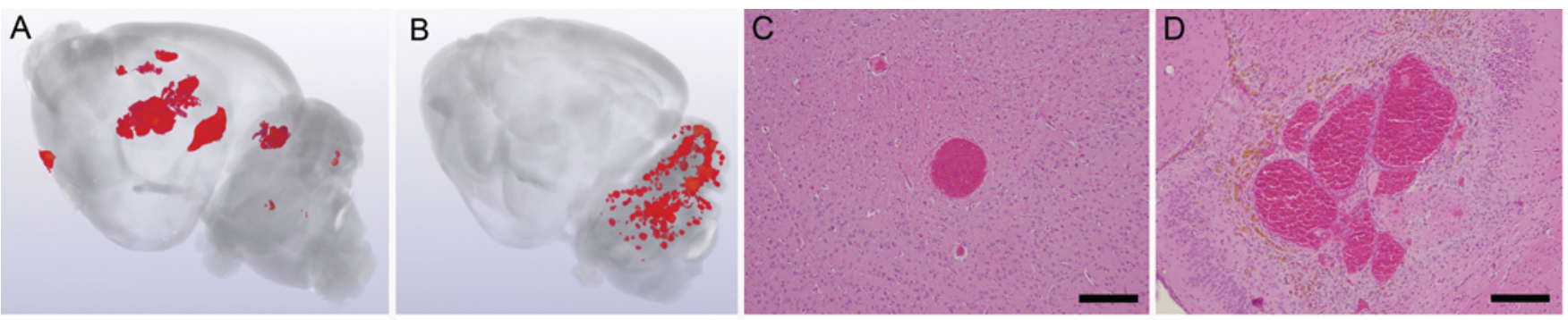

$\mathrm{E}$
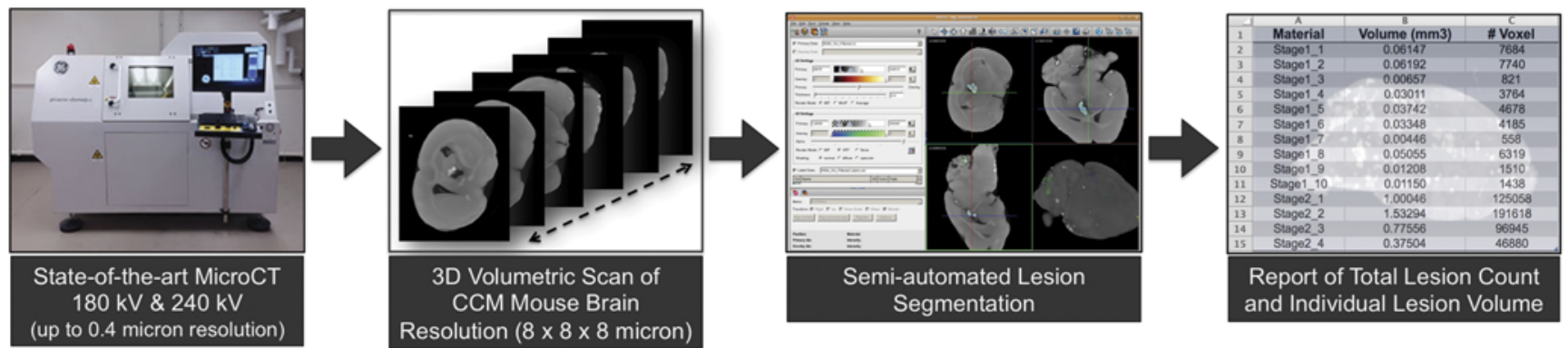

FIG. 5. A: 3D volumetric micro-CT scan of a mouse brain with a rich repertoire of CA lesions, which developed by the 3rd month of life in the $\mathrm{Ccm}^{ \pm} \mathrm{Trp5}^{-/-}$model. B: 3D volumetric micro-CT of a mouse brain with a robust cluster of CA lesions, which developed in the hindbrain by the 10 th day of life, after tamoxifen injection on postnatal day 1 , inducing an endothelial $\mathrm{Ccm} 3^{-/-}$state in mice expressing endothelial-specific $P d g f b$ promoter-driven tamoxifen-regulated Cre recombinase in combination with loxP-flanked Pdcd10 exon 4. C: Photomicrograph illustrating the histological characteristics of a primordial CA lesion, consisting of a single ballooned capillary, without bleeding, a nonheme iron deposit, or inflammatory cell infiltrate (H\&E, bar $=200 \mu M)$. D: Multicavernous mature CA with all the histological features of human lesions with hemosiderin deposits (H\&E, bar $=200 \mu M)$. E: Process of image acquisition by micro-CT, 3D reconstruction, and semiautomated volumetric assessment of the lesion burden.

and vascular lesions, highlighting the role of the neurovascular unit in the human disease..$^{58}$ Loss of $C c m$ function in the epithelium has been shown to provoke intestinal leak and vulnerability to inflammatory bowel disease. ${ }^{102}$ This may, in turn, impact the gut microbiome and affect CA disease severity.

Figure 6 illustrates a number of signaling aberrations correlated with $\mathrm{Ccm}$ gene loss and CA lesion development. A recent study catalogued the comprehensive transcriptome of the human CA lesion neurovascular unit and differentially expressed genes in association with induced loss of $C \mathrm{cml}$ and $C \mathrm{~cm} 3$ genes in cultured murine brain microvascular ECs and the Caenorhabditis elegans nematode, reflecting a rich network of connected genes related to these signaling aberrations. ${ }^{50}$

\section{Implications for Biomarker Development}

Imaging or molecular signatures of biological processes have been proposed for the diagnosis, etiological categorization, severity assessment, and prognostication of disease. The U.S. Food and Drug Administration and National Institutes of Health have designated a Biomarkers Working Group aimed at categorizing contexts of use and defining standards of rigor in biomarker development (https://www. ncbi.nlm.nih.gov/books/NBK326791). ${ }^{6}$ Vascular leak is a fundamental feature of CAs, facilitating hemorrhage and the accompanying accumulation of nonheme iron. A novel MRI application that assesses iron deposition using QSM has been implemented in human CAs (Fig. 3). ${ }^{67,95,96}$ Mean lesional QSM was shown to recapitulate actual iron concentrations measured by mass spectroscopy in surgically resected human CA lesions. Researchers in Chicago and New Mexico optimized DCEQP, another MRI technique that reflects mechanistically postulated vascular hyperpermeability. ${ }^{41,66}$ Both QSM and DCEQP were applied during longitudinal follow-up, with strong interobserver agreement, stability of repeated measurements in clinically stable lesions, and reproducibility across MRI instrument platforms. ${ }^{32}$ Mean lesional QSM and DCEQP increased significantly in CAs manifesting interval symptomatic hemorrhage during longitudinal follow-up, with highly sensitive and specific thresholds. Therefore, QSM and DCEQP were proposed as monitoring biomarkers of lesional bleeding and responses to therapy. ${ }^{109}$ Projects are underway to validate these biomarkers at multiple sites as part of the CASH Trial Readiness initiative,${ }^{72}$ and to test their change as affected by ROCK inhibition using atorvastatin in the first Phase I-IIa proof-of-concept (AT CASH EPOC) trial. ${ }^{74}$

Greater CA disease severity has been identified in association with genetic modifiers causing proinflammatory states. ${ }^{17}$ Chronic CA disease aggressiveness during a patient's lifetime has also been associated with plasma Vitamin D deficiency, an index proinflammatory state. ${ }^{33}$ Other research has assessed plasma proteins with a reported role in the pathology of CA and brain hemorrhage, including angiogenesis, inflammation, EC integrity and permeability, response to stress, cell adhesion, and extracellular matrix remodeling. ${ }^{34}$ Plasma levels of vascular endothelial growth factor (VEGF) and endoglin (ENG) [both $p=0.04$, false discovery rate (FDR) corrected] were lower in pa- 


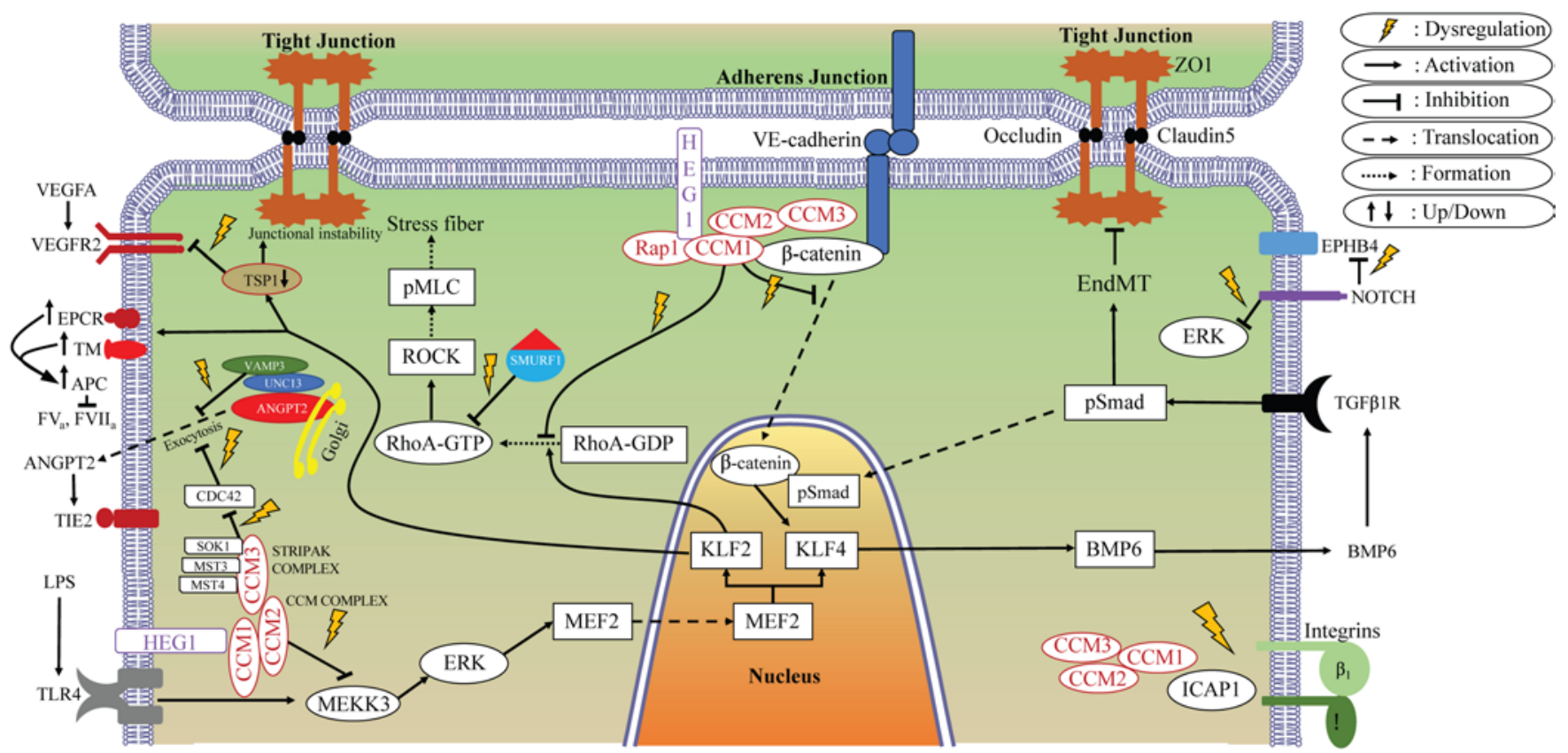

FIG. 6. Diagram of signaling aberrations associated with CA model systems. ANGPT2 = angiopoietin 2; APC = activated protein C; BMP6 = bone morphogenetic protein 6; $\mathrm{CDC42}=$ cell division control protein 42; EndMT = endothelial-to-mesenchymal transition; $\mathrm{EPCR}=$ endothelial protein $\mathrm{C}$ receptor; $\mathrm{EPHB} 4=$ ephrin type- $\mathrm{B}$ receptor $4 ; \mathrm{ERK}=$ extracellular signal-regulated kinase; $\mathrm{FV}_{\mathrm{a}}=$ factor $\mathrm{V}_{\mathrm{a}} ; \mathrm{FVII}_{\mathrm{a}}=$ factor $\mathrm{VII}_{\mathrm{a}} ; \mathrm{GDP}=$ guanosine diphosphate; GTP = guanosine triphosphate; HEG1 = Heart of Glass; ICAP1 = integrin cytoplasmic domain-associated protein-1; KLF = Krüppellike factor; LPS = lipopolysaccharide; MEF2 = myocyte enhancer factor 2; MST3 = serine/threonine kinase 24; MST4 = serine/threonine kinase 26; $\mathrm{NOTCH}=$ translocation-associated Notch protein; pMLC = phosphorylated myosin light-chain; pSmad = transforming growth factor-beta-signaling protein 1; Rap1 = Ras-related protein 1; RhoA = Ras homolog gene family member A; ROCK = Rho-associated protein kinase; SMURF1 = SMAD specific E3 ubiquitin protein ligase 1; SOK1 = serine/threonine kinase 25; STRIPAK = striatin-interacting phosphatase and kinase; TGF $\beta_{1} R=$ transforming growth factor $-\beta_{1}$ receptor; TIE2 = TEK receptor tyrosine kinase; TLR4 = Toll-like receptor 4; TM = thrombomodulin; TSP-1 = thrombospondin-1; UNC13 = UNC13 homolog; VAMP3 = vesicle-associated membrane protein 3; VE-cadherin = vascular endothelial cadherin; VEGFA = vascular endothelial growth factor A; VEGFR2 = VEGF receptor 2; ZO1 = zona occludens-1.

tients who had suffered a symptomatic hemorrhage in the previous 3 months. Hierarchical clustering analysis demonstrated a cluster of four plasma inflammatory cytokines (interleukin [IL] 2, interferon gamma, tumor necrosis factor alpha, and IL1 $\beta$ ) characterizing patients with a "high" inflammatory state associated with seizures $(p=0.02)$ and more than one prior symptomatic hemorrhage during a patient's lifetime $(\mathrm{p}=0.04))^{34}$ More recently, higher plasma levels of IL1 $\beta(p=0.008)$ and sROBO4 $(p=0.03)$, and lower levels of sCD14 (p=0.05), IL6 ( $=0.04)$, and $\operatorname{VEGF}(p=0.0003)$ were reported in patients who suffered a subsequent symptomatic hemorrhage in the year following the plasma sampling. ${ }^{35}$ The individual predictions had only modest sensitivities and specificities (receiver operating characteristic-areas under the curve $0.66-0.82$ ) for individual significant biomarkers after FDR correction. However, a best-weighted combination of the levels of four of these molecules accomplished $86 \%$ sensitivity and $88 \%$ specificity in predicting a symptomatic hemorrhage in the next year, and this was further confirmed in a separate prognostic sample and by rigorous Monte Carlo simulations. Such a level of prognostication had never been shown in brain hemorrhage from any cause. Hence, the combination of multiple biomarkers emerging from mechanistic studies is likely to enhance the rigor of diagnostic and prognostic associations in CA.

\section{Implications for Therapeutic Targeting}

The endothelial phenotype resulting from CCM loss can be rescued by inhibition of mechanistically linked signaling aberrations and the pathogenetic immune response. As discussed previously, familial cases with autosomal dominant inheritance involve one mutated copy of the gene in every cell of the body, while CA lesions develop from somatic biallelic mutations in the second copy of the gene. ${ }^{3,30}$ Sporadic CA lesions also manifest somatic mutations in the same genes, indicating similar pathobiology. ${ }^{64}$ Hence mechanistic therapies targeting the CA lesion are likely operative in both familial and sporadic forms of the disease. In recent experiments, the ROCK inhibitor, statins (with pleiotropic effects including Rho inhibition), and $\mathrm{B}$-cell depletion were shown to decrease hemorrhage in murine CA lesions ${ }^{87,88,92}$ Table 1 summarizes the status of development of candidate therapies, based on mechanistic discoveries and preclinical results, that are potentially aimed at testing in the human disease. Preclinical effects have been demonstrated (fasudil, statins, B-cell depletion) or planned (BA-1049) in mouse models using contemporaneous randomized treatment assignment versus placebo, and blinded outcome assessment per the US National Institute of Neurological Disorders and Stroke guidelines. ${ }^{52}$

The rates at which a new CA develops in familial cases 
TABLE 1. Candidate therapies in CA based on mechanism and status of development

\begin{tabular}{|c|c|c|c|}
\hline Mechanism of Action & Therapy & Testing Status/Evidence & Reference \\
\hline \multirow{3}{*}{ RhoA/ROCK inhibition } & Atorvastatin & Preclinical (clinical trial phase I//la) & $\begin{array}{l}\text { Shenkar et al., } 2019 \\
\text { Polster et al., } 2018^{74}\end{array}$ \\
\hline & Fasudil & Preclinical & McDonald et al., 2012 \\
\hline & BA-1049 (ROCK2 specific inhibitor) & Preclinical & Unpublished* \\
\hline Inflammation & Anti-BR3 antibody (B-cell depletion) & Preclinical & Shi et al., 2016 \\
\hline \multirow[t]{2}{*}{ Reactive oxygen species } & Vitamin D3 & Preclinical (clinical correlation in human) & $\begin{array}{l}\text { Girard et al., } 2016^{33} \\
\text { Gibson et al., } 2015\end{array}$ \\
\hline & Tempol & Preclinical (clinical phase I trial) & Gibson et al., 2015 \\
\hline \multirow{2}{*}{$\begin{array}{l}\text { Angiogenesis and VEGF } \\
\text { inhibition }\end{array}$} & Propranolol & Case reports (open clinical trial) & Zabramski et al., 2016 \\
\hline & Bevacizumab, semaxanib (VEGF inhibition) & Preclinical & DiStefano et al., 2014 \\
\hline Delta-Notch & Sorafenib (multikinase inhibitor) & Preclinical & Wüstehube et al., 2010 \\
\hline \multirow{3}{*}{$\begin{array}{l}\text { Endothelial-to-mesenchymal } \\
\text { transition (TGF- } \beta \text { signaling } \\
\text { cascade) }\end{array}$} & SB431542, LY364947 (SMAD) & Preclinical & Maddaluno et al., 2013 \\
\hline & Sulindac ( $\beta$-catenin) & Preclinical & Bravi et al., 2015 \\
\hline & DMH1 (BMP6) & Preclinical & Maddaluno et al., 2013 \\
\hline $\begin{array}{l}\text { Restoration of autophagy } \\
\text { (mTOR-ULK1) }\end{array}$ & mTOR inhibitors & Preclinical & Marchi et al., 2015 \\
\hline \multirow{3}{*}{ MEKK2/ERK/KLF2-4 } & TLR4 inhibition compounds & Preclinical & Tang et al., 2017 \\
\hline & BIX02189 (anti-MEK5) & Preclinical & Zhou et al., 2016 \\
\hline & XMD17-109 (anti-ERK5) & Preclinical & Zhou et al., 2016 \\
\hline TSP-1 & TSP-1 replacement (TSR3) & Preclinical (clinical correlation in human) & Lopez-Ramirez et al., 2017 \\
\hline TM and EPCR & TM and EPCR inhibitors & Preclinical (clinical correlation in human) & Lopez-Ramirez et al., 2019 \\
\hline Microbiome & - & Preclinical & Tang et al., 2017 \\
\hline
\end{tabular}

BMP6 = bone morphogenetic protein 6; BR3 = BLyS receptor 3/BAFF-R; Delta-Notch = Delta ligand-mediated Notch signaling; DMH1 = dorsomorphin homolog 1; EPCR = endothelial protein $\mathrm{C}$ receptor; $\mathrm{ERK}=$ extracellular signal-regulated kinase; $\mathrm{KLF}=$ Krüppel-like factor; $\mathrm{MEK} 5$ = dual specificity mitogen-activated protein kinase $5 ; \mathrm{mTOR}=$ mammalian target of rapamycin; RhoA = Ras homolog gene family member $\mathrm{A} ; \mathrm{ROCK}=$ Rho-associated protein kinase; SMAD = transforming growth factor-beta signaling protein 1 ; TGF- $\beta=$ transforming growth factor-beta; TM = thrombomodulin; TSP $-1=$ thrombospondin-1; TSR3 = transferase ribosome maturation factor 3; ULK1 = Unc-51 like autophagy activating kinase $1 ;-=$ not applicable.

${ }^{*}$ Collaboration among BioAxone BioSciences, Inc., University of Chicago, Duke University, and LA BioMed.

and first symptomatic hemorrhage in asymptomatic CAs are far too low to allow meaningful testing or compel primary prevention strategies. CASH lesions, for which resection is not undertaken because the majority are in deep and brainstem locations, are the most likely to be followed expectantly according to current evidence-based guidelines. ${ }^{2}$ There is a clinical equipoise for testing novel therapies with the goal of preventing rebleeding in such cases. It would be appropriate to develop a drug that stabilizes the CASH lesion. This would mitigate the costs and neurological sequelae of repeated hemorrhage and of resection in many patients. Based on data from natural history studies, the therapeutic benefit for secondary prevention (symptomatic rebleed) would be maximal within 2-3 years after a recent symptomatic bleed.

The clearest pathway for drug repurposing involves currently approved statin drugs, with ROCK inhibition pleiotropic effect at high doses. Statins may be ready for Phase III multisite trials in about 5 years, pending the results of an ongoing Phase I-IIa single-site trial (AT CASH EPOC, NCT02603328; registered at clinicaltrials.gov) aimed at a biomarker proof-of-concept effect and preliminary safety of atorvastatin versus placebo. Propranolol has been proposed based on its effect in another entity, infantile hemangioma of the head and neck, and limited uncontrolled case reports in brain CA, ${ }^{53,108}$ albeit without mechanistic studies or preclinical evidence to date. A pragmatic propranolol trial was initiated in Italy (Treat_CCM, NCT03589014; registered at clinicaltrials.gov), although it is admittedly underpowered and any signal of favorable results will be considered exploratory, requiring a more definitive Phase III study. Biologics affecting B-cell depletion ${ }^{10}$ may generate interest in the development for a new indication in CASH. While new drug developments of ROCK-2 inhibitor BA-1049 (US Patent \#10106525) and Tempol ${ }^{31}$ benefit from respective commitments by BioAxone, Inc. and Recursion Pharmaceuticals, these new drugs still require completion of preclinical testing, toxicology, pharmacobiological optimization, and Phase I-II studies. There has also been expressed interest by teams in the European Union to develop the drug sulindac sulfone for CA..$^{14,15}$

\section{Cavernous Angioma as a Paradigm Disease}

$\mathrm{CA}$ is a paradigm of a common neurovascular lesion with uncommon but consequential clinical sequelae. With Mendelian inheritance of familial cases, identical somatic mutations in sporadic cases, and faithful murine models of disease, several mechanisms of lesion genesis and progression have been elucidated. The disease has emerged as a 
model of pathology involving vascular proliferation and dysmorphism, hemorrhagic angiopathy, brain iron deposition, lesional epileptogenesis, neurovascular immune disorder, and gut-brain axis. Investigations from many fields of science have been translated to help elucidate CA pathobiology and to develop biomarkers and putative therapies. These have included molecular genetics, vascular biology, immunology, microbial ecology, MR physics, biomedical engineering, transcriptomics, computational biology, biomarker science, pharmacology, genetic and population epidemiology, and trial readiness and design. It is a model of translational neuroscience with neurosurgical leadership, leveraging clinical programs, human subjects research, the mining of surgical tissue, and collaborations with "big science" teams.

Research on CA has contributed novel concepts in medicine. It is the first disease shown to be caused by genes essential for embryonic cardiovascular development, in which mutation later in life, on brain microvascular ECs, causes a focal neurovascular pathology. It is also the first disease in which gene heterozygosity, in the absence of lesions, causes diffuse systemic vascular and epithelial hyperpermeability. And it is the first disease where a gutbrain axis has been mechanistically linked to specific signaling on brain microvascular ECs. Spectacular discoveries and benefit to patients await similar deconstruction of other neurosurgical diseases.

\section{Acknowledgments}

This paper was written with contributions by the following Neurovascular Surgery Research collaborators: Romuald Girard, $\mathrm{PhD}$, Janne Koskimäki, MD, PhD, and Robert Shenkar, PhD.

Much of the science and clinical insights conveyed herein would not be possible without the inspiration and trust by CA patients and families, and the dedication of their support and advocacy group, the Angioma Alliance (www.angioma.org); the diligence and dedication of the research staff and trainees, histologists, bioengineer, statistician, and computational biologist in the Awad Laboratory (https://surgeryresearch.uchicago.edu/ page/issam-awad); the clinical staff and researchers in the CCM Program of Excellence (www.uchicagomedicine.org/ccm); and the core facilities at the University of Chicago Biological Sciences Division. We also recognize longstanding and productive collaborations with the laboratories of Douglas Marchuk at Duke University, Mark Ginsberg at the University of California San Diego, Mark Kahn at the University of Pennsylvania, and Brent Derry at Toronto Sick Kids Hospital; as well as clinical research collaborations with the teams of Daniel Hanley at Johns Hopkins Medical Institutions, Helen Kim at the University of California San Francisco, and Kelly Flemming at the Mayo Clinic in Rochester, Minnesota. Figure $1 \mathrm{~A}$ artistic illustration by Lydia M. Johns.

\section{References}

1. Abdulrauf SI, Kaynar MY, Awad IA: A comparison of the clinical profile of cavernous malformations with and without associated venous malformations. Neurosurgery 44:41-47, 1999

2. Akers A, Al-Shahi Salman R, Awad IA, Dahlem K, Flemming K, Hart B, et al: Synopsis of Guidelines for the Clinical Management of Cerebral Cavernous Malformations: consensus recommendations based on systematic literature review by the Angioma Alliance Scientific Advisory Board Clinical Experts Panel. Neurosurgery 80:665-680, 2017
3. Akers AL, Johnson E, Steinberg GK, Zabramski JM, Marchuk DA: Biallelic somatic and germline mutations in cerebral cavernous malformations (CCMs): evidence for a two-hit mechanism of CCM pathogenesis. Hum Mol Genet 18:919-930, 2009

4. Al-Shahi Salman R, Berg MJ, Morrison L, Awad IA: Hemorrhage from cavernous malformations of the brain: definition and reporting standards. Stroke 39:3222-3230, 2008

5. Al-Shahi Salman R, Hall JM, Horne MA, Moultrie F, Josephson CB, Bhattacharya JJ, et al: Untreated clinical course of cerebral cavernous malformations: a prospective, population-based cohort study. Lancet Neurol 11:217-224, 2012

6. Amur SG, Sanyal S, Chakravarty AG, Noone MH, Kaiser J, McCune S, et al: Building a roadmap to biomarker qualification: challenges and opportunities. Biomarkers Med 9:1095-1105, 2015

7. Awad I, Jabbour P: Cerebral cavernous malformations and epilepsy. Neurosurg Focus 21(1):e7, 2006

8. Awad IA, Robinson JR Jr, Mohanty S, Estes ML: Mixed vascular malformations of the brain: clinical and pathogenetic considerations. Neurosurgery 33:179-188, 1993

9. Badhiwala JH, Farrokhyar F, Alhazzani W, Yarascavitch B, Aref M, Algird A, et al: Surgical outcomes and natural history of intramedullary spinal cord cavernous malformations: a single-center series and meta-analysis of individual patient data: clinic article. J Neurosurg Spine 21:662-676, 2014

10. Barun B, Bar-Or A: Treatment of multiple sclerosis with anti-CD20 antibodies. Clin Immunol 142:31-37, 2012

11. Baumann CR, Schuknecht B, Lo Russo G, Cossu M, Citterio A, Andermann F, et al: Seizure outcome after resection of cavernous malformations is better when surrounding hemosiderin-stained brain also is removed. Epilepsia 47:563-566, 2006

12. Bergametti F, Denier C, Labauge P, Arnoult M, Boetto $\mathrm{S}$, Clanet M, et al: Mutations within the programmed cell death 10 gene cause cerebral cavernous malformations. Am J Hum Genet 76:42-51, 2005

13. Bos D, Poels MM, Adams HH, Akoudad S, Cremers LG, Zonneveld HI, et al: Prevalence, clinical management, and natural course of incidental findings on brain MR images: the population-based Rotterdam Scan Study. Radiology 281:507-515, 2016

14. Bravi L, Malinverno M, Pisati F, Rudini N, Cuttano R, Pallini R, et al: Endothelial cells lining sporadic cerebral cavernous malformation cavernomas undergo endothelialto-mesenchymal transition. Stroke 47:886-890, 2016

15. Bravi L, Rudini N, Cuttano R, Giampietro C, Maddaluno L, Ferrarini L, et al: Sulindac metabolites decrease cerebrovascular malformations in CCM3-knockout mice. Proc Natl Acad Sci U S A 112:8421-8426, 2015

16. Campbell PG, Jabbour P, Yadla S, Awad IA: Emerging clinical imaging techniques for cerebral cavernous malformations: a systematic review. Neurosurg Focus 29(3):E6, 2010

17. Choquet H, Pawlikowska L, Nelson J, McCulloch CE, Akers A, Baca B, et al: Polymorphisms in inflammatory and immune response genes associated with cerebral cavernous malformation type 1 severity. Cerebrovasc Dis 38:433440,2014

18. Choudhri O, Karamchandani J, Gooderham P, Steinberg GK: Flexible omnidirectional carbon dioxide laser as an effective tool for resection of brainstem, supratentorial, and intramedullary cavernous malformations. Neurosurgery $\mathbf{1 0}$ (Suppl 1):34, 43-45, 2014

19. Cohen DS, Zubay GP, Goodman RR: Seizure outcome after lesionectomy for cavernous malformations. J Neurosurg 83:237-242, 1995 
20. Craig HD, Günel M, Cepeda O, Johnson EW, Ptacek L, Steinberg GK, et al: Multilocus linkage identifies two new loci for a Mendelian form of stroke, cerebral cavernous malformation, at 7p15-13 and 3q25.2-27. Hum Mol Genet 7:1851-1858, 1998

21. Cushing H, Bailey P: Tumors Arising From the BloodVessels of the Brain; Angiomatous Malformations and Hemangioblastomas. Springfield, IL: CC Thomas, 1928

22. Cutsforth-Gregory JK, Lanzino G, Link MJ, Brown RD Jr, Flemming KD: Characterization of radiation-induced cavernous malformations and comparison with a nonradiation cavernous malformation cohort. J Neurosurg 122:12141222,2015

23. de Champfleur NM, Langlois C, Ankenbrandt WJ, Le Bars E, Leroy MA, Duffau H, et al: Magnetic resonance imaging evaluation of cerebral cavernous malformations with susceptibility-weighted imaging. Neurosurgery 68:641-648, 2011

24. de Souza JM, Domingues RC, Cruz LC Jr, Domingues FS, Iasbeck T, Gasparetto EL: Susceptibility-weighted imaging for the evaluation of patients with familial cerebral cavernous malformations: a comparison with T2-weighted fast spin-echo and gradient-echo sequences. AJNR Am J Neuroradiol 29:154-158, 2008

25. Detter MR, Snellings DA, Marchuk DA: Cerebral cavernous malformations develop through clonal expansion of mutant endothelial cells. Circ Res 123:1143-1151, 2018

26. DiStefano PV, Kuebel JM, Sarelius IH, Glading AJ: KRIT1 protein depletion modifies endothelial cell behavior via increased vascular endothelial growth factor (VEGF) signaling. J Biol Chem 289:33054-33065, 2014

27. Flores BC, Whittemore AR, Samson DS, Barnett SL: The utility of preoperative diffusion tensor imaging in the surgical management of brainstem cavernous malformations. J Neurosurg 122:653-662, 2015

28. Gallione CJ, Solatycki A, Awad IA, Weber JL, Marchuk DA: A founder mutation in the Ashkenazi Jewish population affecting messenger RNA splicing of the CCM2 gene causes cerebral cavernous malformations. Genet Med 13:662-666, 2011

29. Gault J, Sain S, Hu LJ, Awad IA: Spectrum of genotype and clinical manifestations in cerebral cavernous malformations. Neurosurgery 59:1278-1285, 2006

30. Gault J, Shenkar R, Recksiek P, Awad IA: Biallelic somatic and germ line CCM1 truncating mutations in a cerebral cavernous malformation lesion. Stroke 36:872-874, 2005

31. Gibson CC, Zhu W, Davis CT, Bowman-Kirigin JA, Chan AC, Ling J, et al: Strategy for identifying repurposed drugs for the treatment of cerebral cavernous malformation. Circulation 131:289-299, 2015

32. Girard R, Fam MD, Zeineddine HA, Tan H, Mikati AG, Shi $\mathrm{C}$, et al: Vascular permeability and iron deposition biomarkers in longitudinal follow-up of cerebral cavernous malformations. J Neurosurg 127: 102-110, 2017

33. Girard R, Khanna O, Shenkar R, Zhang L, Wu M, Jesselson $\mathrm{M}$, et al: Peripheral plasma vitamin D and non-HDL cholesterol reflect the severity of cerebral cavernous malformation disease. Biomarkers Med 10:255-264, 2016

34. Girard R, Zeineddine HA, Fam MD, Mayampurath A, Cao Y, Shi C, et al: Plasma biomarkers of inflammation reflect seizures and hemorrhagic activity of cerebral cavernous malformations. Transl Stroke Res 9:34-43, 2018

35. Girard R, Zeineddine HA, Koskimäki J, Fam MD, Cao Y, Shi C, et al: Plasma biomarkers of inflammation and angiogenesis predict cerebral cavernous malformation symptomatic hemorrhage or lesional growth. Circ Res 122:17161721,2018

36. Girard R, Zeineddine HA, Orsbon C, Tan H, Moore T, Hobson N, et al: Micro-computed tomography in murine models of cerebral cavernous malformations as a paradigm for brain disease. J Neurosci Methods 271:14-24, 2016

37. Gross BA, Batjer HH, Awad IA, Bendok BR: Cavernous malformations of the basal ganglia and thalamus.

Neurosurgery 65:7-19, 2009

38. Gross BA, Batjer HH, Awad IA, Bendok BR, Du R: Brainstem cavernous malformations: 1390 surgical cases from the literature. World Neurosurg 80:89-93, 2013

39. Günel M, Awad IA, Anson J, Lifton RP: Mapping a gene causing cerebral cavernous malformation to 7q11.2-q21. Proc Natl Acad Sci U S A 92:6620-6624, 1995

40. Gunel M, Awad IA, Finberg K, Anson JA, Steinberg GK, Batjer $\mathrm{HH}$, et al: A founder mutation as a cause of cerebral cavernous malformation in Hispanic Americans. N Engl J Med 334:946-951, 1996

41. Hart BL, Taheri S, Rosenberg GA, Morrison LA: Dynamic contrast-enhanced MRI evaluation of cerebral cavernous malformations. Transl Stroke Res 4:500-506, 2013

42. Heckl S, Aschoff A, Kunze S: Radiation-induced cavernous hemangiomas of the brain: a late effect predominantly in children. Cancer 94:3285-3291, 2002

43. Hemphill JC III, Greenberg SM, Anderson CS, Becker K, Bendok BR, Cushman M, et al: Guidelines for the management of spontaneous intracerebral hemorrhage: a guideline for healthcare professionals from the American Heart Association/American Stroke Association. Stroke 46:20322060, 2015

44. Horne MA, Flemming KD, Su IC, Stapf C, Jeon JP, Li D, et al: Clinical course of untreated cerebral cavernous malformations: a meta-analysis of individual patient data. Lancet Neurol 15: 166-173, 2016

45. Hsu CC, Stanford BA: The Delphi technique: making sense of consensus. Pract Assess Res Eval 12:1-8, 2007

46. Jenny Zhou H, Qin L, Zhang H, Tang W, Ji W, He Y, et al: Endothelial exocytosis of angiopoietin-2 resulting from CCM3 deficiency contributes to cerebral cavernous malformation. Nat Med 22:1033-1042, 2016

47. Kanaan I, Jallu A, Alwatban J, Patay Z, Hessler R: Extraaxial cavernous hemangioma: two case reports. Skull Base 11:287-295, 2001

48. Kleaveland B, Zheng X, Liu JJ, Blum Y, Tung JJ, Zou Z, et al: Regulation of cardiovascular development and integrity by the heart of glass-cerebral cavernous malformation protein pathway. Nat Med 15:169-176, 2009

49. Kondziolka D, Lunsford LD, Coffey RJ, Bissonette DJ, Flickinger JC: Stereotactic radiosurgery of angiographically occult vascular malformations: indications and preliminary experience. Neurosurgery 27:892-900, 1990

50. Koskimäki J, Girard R, Li Y, Saadat L, Zeineddine HA, Lightle R, et al: Comprehensive transcriptome analysis of cerebral cavernous malformation across multiple species and genotypes. JCI Insight 4:e126167, 2019

51. Laberge-le Couteulx S, Jung HH, Labauge P, Houtteville JP, Lescoat C, Cecillon M, et al: Truncating mutations in CCM1, encoding KRIT1, cause hereditary cavernous angiomas. Nat Genet 23:189-193, 1999

52. Landis SC, Amara SG, Asadullah K, Austin CP, Blumenstein R, Bradley EW, et al: A call for transparent reporting to optimize the predictive value of preclinical research. Nature 490:187-191, 2012

53. Léauté-Labrèze C, Hoeger $\mathrm{P}$, Mazereeuw-Hautier J, Guibaud L, Baselga E, Posiunas G, et al: A randomized, controlled trial of oral propranolol in infantile hemangioma. N Engl J Med 372:735-746, 2015

54. Lee SH, Choi HJ, Shin HS, Choi SK, Oh IH, Lim YJ: Gamma Knife radiosurgery for brainstem cavernous malformations: should a patient wait for the rebleed? Acta Neurochir (Wien) 156:1937-1946, 2014

55. Liquori CL, Berg MJ, Siegel AM, Huang E, Zawistowski 
JS, Stoffer T, et al: Mutations in a gene encoding a novel protein containing a phosphotyrosine-binding domain cause type 2 cerebral cavernous malformations. Am J Hum Genet 73:1459-1464, 2003

56. Lopez-Ramirez MA, Fonseca G, Zeineddine HA, Girard R, Moore T, Pham A, et al: Thrombospondin1 (TSP1) replacement prevents cerebral cavernous malformations. J Exp Med 214:3331-3346, 2017

57. Lopez-Ramirez MA, Pham A, Girard R, Wyseure T, Hale P, Yamashita A, et al: Cerebral cavernous malformations form an anticoagulant vascular domain in humans and mice. Blood 133:193-204, 2019

58. Louvi A, Chen L, Two AM, Zhang H, Min W, Günel M: Loss of cerebral cavernous malformation $3(\mathrm{Ccm} 3)$ in neuroglia leads to CCM and vascular pathology. Proc Natl Acad Sci U S A 108:3737-3742, 2011

59. Lu XY, Sun H, Xu JG, Li QY: Stereotactic radiosurgery of brainstem cavernous malformations: a systematic review and meta-analysis. J Neurosurg 120:982-987, 2014

60. Maddaluno L, Rudini N, Cuttano R, Bravi L, Giampietro C, Corada M, et al: EndMT contributes to the onset and progression of cerebral cavernous malformations. Nature 498:492-496, 2013

61. Marchi S, Corricelli M, Trapani E, Bravi L, Pittaro A, Delle Monache S, et al: Defective autophagy is a key feature of cerebral cavernous malformations. EMBO Mol Med 7:1403-1417, 2015

62. McCormick WF: The pathology of vascular ("arteriovenous") malformations. J Neurosurg 24:807-816, 1966

63. McDonald DA, Shenkar R, Shi C, Stockton RA, Akers AL, Kucherlapati MH, et al: A novel mouse model of cerebral cavernous malformations based on the two-hit mutation hypothesis recapitulates the human disease. Hum Mol Genet 20:211-222, 2011

64. McDonald DA, Shi C, Shenkar R, Gallione CJ, Akers AL, $\mathrm{Li} \mathrm{S}$, et al: Lesions from patients with sporadic cerebral cavernous malformations harbor somatic mutations in the CCM genes: evidence for a common biochemical pathway for CCM pathogenesis. Hum Mol Genet 23:4357-4370, 2014

65. McDonald DA, Shi C, Shenkar R, Stockton RA, Liu F, Ginsberg MH, et al: Fasudil decreases lesion burden in a murine model of cerebral cavernous malformation disease. Stroke 43:571-574, 2012

66. Mikati AG, Khanna O, Zhang L, Girard R, Shenkar R, Guo $\mathrm{X}$, et al: Vascular permeability in cerebral cavernous malformations. J Cereb Blood Flow Metab 35:1632-1639, 2015

67. Mikati AG, Tan H, Shenkar R, Li L, Zhang L, Guo X, et al: Dynamic permeability and quantitative susceptibility: related imaging biomarkers in cerebral cavernous malformations. Stroke 45:598-601, 2014

68. Moore SA, Brown RD Jr, Christianson TJ, Flemming KD: Long-term natural history of incidentally discovered cavernous malformations in a single-center cohort. J Neurosurg 120:1188-1192, 2014

69. Moultrie F, Horne MA, Josephson CB, Hall JM, Counsell $\mathrm{CE}$, Bhattacharya JJ, et al: Outcome after surgical or conservative management of cerebral cavernous malformations. Neurology 83:582-589, 2014

70. Noshiro S, Mikami T, Kataoka-Sasaki Y, Sasaki M, Ohnishi $\mathrm{H}$, Ohtaki S, et al: Co-expression of tissue factor and IL-6 in immature endothelial cells of cerebral cavernous malformations. J Clin Neurosci 37:83-90, 2017

71. Pasqualin A, Meneghelli P, Giammarusti A, Turazzi S: Results of surgery for cavernomas in critical supratentorial areas. Acta Neurochir Suppl 119:117-123, 2014

72. Polster SP, Cao Y, Carroll T, Flemming K, Girard R, Hanley D, et al: Trial readiness in cavernous angiomas with symptomatic hemorrhage (CASH). Neurosurgery 84:954964, 2019

73. Polster SP, Horowitz PM, Awad IA, Gluth MB: Combined petrosal approach. Curr Opin Otolaryngol Head Neck Surg 26:293-301, 2018

74. Polster SP, Stadnik A, Akers AL, Cao Y, Christoforidis GA, Fam MD, et al: Atorvastatin Treatment of Cavernous Angiomas with Symptomatic Hemorrhage Exploratory Proof of Concept (AT CASH EPOC) Trial. Neurosurgery [epub ahead of print], 2018

75. Poorthuis M, Samarasekera N, Kontoh K, Stuart I, Cope B, Kitchen N, et al: Comparative studies of the diagnosis and treatment of cerebral cavernous malformations in adults: systematic review. Acta Neurochir (Wien) 155:643-649, 2013

76. Retta SF, Glading AJ: Oxidative stress and inflammation in cerebral cavernous malformation disease pathogenesis: two sides of the same coin. Int J Biochem Cell Biol 81 (Pt B):254-270, 2016

77. Rigamonti D, Drayer BP, Johnson PC, Hadley MN, Zabramski J, Spetzler RF: The MRI appearance of cavernous malformations (angiomas). J Neurosurg 67:518-524, 1987

78. Robinson JR Jr, Awad IA, Magdinec M, Paranandi L: Factors predisposing to clinical disability in patients with cavernous malformations of the brain. Neurosurgery 32:730-736, 1993

79. Robinson JR Jr, Awad IA, Masaryk TJ, Estes ML: Pathological heterogeneity of angiographically occult vascular malformations of the brain. Neurosurgery 33:547-555, 1993

80. Rosenow F, Alonso-Vanegas MA, Baumgartner C, Blümcke I, Carreño M, Gizewski ER, et al: Cavernoma-related epilepsy: review and recommendations for managementreport of the Surgical Task Force of the ILAE Commission on Therapeutic Strategies. Epilepsia 54:2025-2035, 2013

81. Rothbart D, Awad IA, Lee J, Kim J, Harbaugh R, Criscuolo GR: Expression of angiogenic factors and structural proteins in central nervous system vascular malformations. Neurosurgery 38:915-925, 1996

82. Russell D, Rubinstein L, Lumsden C: Tumors and hamartomas of blood vessels, in: Pathology of Tumors of the Central Nervous System. London: Edward Arnold, 1959, pp 72-92

83. Russell DS: Spontaneous intracranial haemorrhage. Proc R Soc Med 47:689-693, 1954

84. Santoro A, Piccirilli M, Bristot R, di Norcia V, Salvati M, Delfini R: Extradural spinal cavernous angiomas: report of seven cases. Neurosurg Rev 28:313-319, 2005

85. Schlosser MJ, McCarthy G, Fulbright RK, Gore JC, Awad IA: Cerebral vascular malformations adjacent to sensorimotor and visual cortex. Functional magnetic resonance imaging studies before and after therapeutic intervention. Stroke 28:1130-1137, 1997

86. Schmolck K: Ueber Hemangiome im Bereich des Brucke [Dissertation]. Gissen, Germany: University of Gissen, 1912

87. Shenkar R, Peiper A, Pardo H, Moore T, Lightle R, Girard $\mathrm{R}$, et al: Rho kinase inhibition blunts lesion development and hemorrhage in murine models of aggressive Pdcd10/ Ccm3 disease. Stroke 50:738-744, 2019

88. Shenkar R, Shi C, Austin C, Moore T, Lightle R, Cao Y, et al: RhoA kinase inhibition with fasudil versus simvastatin in murine models of cerebral cavernous malformations. Stroke 48:187-194, 2017

89. Shenkar R, Shi C, Rebeiz T, Stockton RA, McDonald DA, Mikati AG, et al: Exceptional aggressiveness of cerebral cavernous malformation disease associated with PDCD10 mutations. Genet Med 17:188-196, 2015 
90. Shi C, Shenkar R, Du H, Duckworth E, Raja H, Batjer HH, et al: Immune response in human cerebral cavernous malformations. Stroke 40:1659-1665, 2009

91. Shi C, Shenkar R, Kinloch A, Henderson SG, Shaaya M, Chong AS, et al: Immune complex formation and in situ B-cell clonal expansion in human cerebral cavernous malformations. J Neuroimmunol 272:67-75, 2014

92. Shi C, Shenkar R, Zeineddine HA, Girard R, Fam MD, Austin C, et al: B-cell depletion reduces the maturation of cerebral cavernous malformations in murine models. $\mathbf{J}$ Neuroimmune Pharmacol 11:369-377, 2016

93. Stockton RA, Shenkar R, Awad IA, Ginsberg MH: Cerebral cavernous malformations proteins inhibit Rho kinase to stabilize vascular integrity. J Exp Med 207:881-896, 2010

94. Sze G, Krol G, Olsen WL, Harper PS, Galicich JH, Heier LA, et al: Hemorrhagic neoplasms: MR mimics of occult vascular malformations. AJR Am J Roentgenol 149:12231230,1987

95. Tan H, Liu T, Wu Y, Thacker J, Shenkar R, Mikati AG, et al: Evaluation of iron content in human cerebral cavernous malformation using quantitative susceptibility mapping. Invest Radiol 49:498-504, 2014

96. Tan H, Zhang L, Mikati AG, Girard R, Khanna O, Fam $\mathrm{MD}$, et al: Quantitative susceptibility mapping in cerebral cavernous malformations: clinical correlations. AJNR Am J Neuroradiol 37:1209-1215, 2016

97. Tang AT, Choi JP, Kotzin JJ, Yang Y, Hong CC, Hobson $\mathrm{N}$, et al: Endothelial TLR4 and the microbiome drive cerebral cavernous malformations. Nature 545:305-310, 2017

98. Tanino T, Kanasaki Y, Tahara T, Michimoto K, Kodani K, Kakite S, et al: Radiation-induced microbleeds after cranial irradiation: evaluation by phase-sensitive magnetic resonance imaging with 3.0 tesla. Yonago Acta Med 56:7-12, 2013

99. Uranishi R, Baev NI, Kim JH, Awad IA: Vascular smooth muscle cell differentiation in human cerebral vascular malformations. Neurosurgery 49:671-680, 2001

100. Virchow RLK: Die krankhaften Geschwulste; Dreissig Vorlesungen, gehalten wahrend des Wintersemesters 1862-1863 an der Universitat zu Berlin. Berlin: Hirschwald, 1863

101. von der Brelie C, Kuczaty S, von Lehe M: Surgical management and long-term outcome of pediatric patients with different subtypes of epilepsy associated with cerebral cavernous malformations. J Neurosurg Pediatr 13:699-705, 2014

102. Wang Y, Li Y, Zou J, Polster SP, Lightle R, Moore T, et al: The cerebral cavernous malformation disease causing gene KRIT1 participates in intestinal epithelial barrier maintenance and regulation. FASEB J 33:2132-2143, 2019

103. Whitehead KJ, Chan AC, Navankasattusas S, Koh W, London NR, Ling J, et al: The cerebral cavernous malformation signaling pathway promotes vascular integrity via Rho GTPases. Nat Med 15:177-184, 2009

104. Willie JT, Malcolm JG, Stern MA, Lowder LO, Neill SG, Cabaniss BT, et al: Safety and effectiveness of stereotactic laser ablation for epileptogenic cerebral cavernous malformations. Epilepsia 60:220-232, 2019
105. Winkler D, Lindner D, Strauss G, Richter A, Schober R, Meixensberger J: Surgery of cavernous malformations with and without navigational support-a comparative study. Minim Invasive Neurosurg 49:15-19, 2006

106. Wong JH, Awad IA, Kim JH: Ultrastructural pathological features of cerebrovascular malformations: a preliminary report. Neurosurgery 46:1454-1459, 2000

107. Wüstehube J, Bartol A, Liebler SS, Brütsch R, Zhu Y, Felbor U, et al: Cerebral cavernous malformation protein CCM1 inhibits sprouting angiogenesis by activating DELTA-NOTCH signaling. Proc Natl Acad Sci U S A 107:12640-12645, 2010

108. Zabramski JM, Kalani MY, Filippidis AS, Spetzler RF: Propranolol treatment of cavernous malformations with symptomatic hemorrhage. World Neurosurg 88:631-639, 2016

109. Zeineddine HA, Girard R, Cao Y, Hobson N, Fam MD, Stadnik A, et al: Quantitative susceptibility mapping as a monitoring biomarker in cerebral cavernous malformations with recent hemorrhage. J Magn Reson Imaging 47:11331138,2018

110. Zeineddine HA, Girard R, Saadat L, Shen L, Lightle R, Moore T, et al: Phenotypic characterization of murine models of cerebral cavernous malformations. Lab Invest 99:319-330, 2019

111. Zhang P, Liu L, Cao Y, Wang S, Zhao J: Cerebellar cavernous malformations with and without associated developmental venous anomalies. BMC Neurol 13:134, 2013

112. Zhou H, Miller D, Schulte DM, Benes L, Rosenow F, Bertalanffy H, et al: Transsulcal approach supported by navigation-guided neurophysiological monitoring for resection of paracentral cavernomas. Clin Neurol Neurosurg 111:69-78, 2009

113. Zhou Z, Tang AT, Wong WY, Bamezai S, Goddard LM, Shenkar R, et al: Cerebral cavernous malformations arise from endothelial gain of MEKK3-KLF2/4 signalling. Nature 532:122-126, 2016

\section{Disclosures}

The authors acknowledge support by the National Institute of Neurological Disorders and Stroke for CCM research through K24, R01, R21, U01 and P01 grants since 1998, and currently through 2022.

\section{Author Contributions}

Conception and design: both authors. Acquisition of data: both authors. Analysis and interpretation of data: both authors. Drafting the article: both authors. Critically revising the article: both authors. Reviewed submitted version of manuscript: Polster. Approved the final version of the manuscript on behalf of both authors: Awad.

\section{Correspondence}

Issam A. Awad: University of Chicago Medicine and Biological Sciences, Chicago, IL. iawad@uchicago.edu. 